\title{
What role does metal allergy sensitization play in total knee arthroplasty revision?
}

\author{
David R. Lionberger ${ }^{1 *}$, Justin Samorajski ${ }^{2}$, Charlie D. Wilson ${ }^{3}$ and Andreana Rivera ${ }^{4}$
}

\begin{abstract}
Background: Clinicians are often faced with the decision whether to revise a painful total knee replacement in patients who have chronic vague pain with no apparent explanation. A sensitive metal testing assay called the lymphocyte stimulation test has been used to detect nickel sensitization in patients with orthopedic implants. We hypothesize that nickel sensitization plays a role in the pathology of failed joint arthroplasty in patients with unexplained dissatisfaction.

Methods: 32 patients with symptomatic total knee arthroplasty without obvious mechanical findings were tested prior to revision surgery. 19 nickel-sensitized and 13 non-sensitized patients were compared by cell counts of synovium surgical specimens for $\mathrm{CD}^{+}$and $\mathrm{CD}^{+}$cell lines. Patients were then revised with ceramic-coated implants. Secondary evaluation of functional outcomes, range of motion, and pain relief were assessed.

Results: Nickel-sensitive patients showed a statistical increase in $\mathrm{CD} 4^{+}$reactivity compared to $\mathrm{CD} 8^{+}$reactivity. The ratio of $\mathrm{CD}^{+} / \mathrm{CD}^{+} \mathrm{T}$ lymphocytes was 1.28 in nickel-sensitive patients versus 0.76 in the control $(p=0.009)$. There was no difference in functional scores, clinical scores, or range of motion after revision.

Conclusions: This study provides objective data via histological analysis in support of a nickel allergic sensitization in failed arthroplasties where clinical and/or radiographic abnormalities may not be apparent. Biopsy for $\mathrm{CD} 4^{+} / \mathrm{CD} 8^{+}$ cell counts may provide further proof of the existence of nickel sensitization in lymphocyte stimulation test positive patients, and more importantly, may implore the surgeon to consider low nickel implant design in these patients.
\end{abstract}

Keywords: Metal allergy, Wear byproducts, Hypersensitivity, Ceramic implant, Failed knee arthroplasty

\section{Background}

Allergic reaction to orthopedic implant metals has not received much attention in the past largely due to the difficulty to test and quantify allergic responses. However, in the last decade, orthopedic surgery has wrestled with metal-wear complications, one of which is the metal-on-metal (MOM) total hip replacement. Until the findings of MOM sensitivity became apparent, allergic sensitization was not perceived as an area of concern (Beecker et al. 2009; Handa et al. 2003; Repantis et al. 2013; Watters et al. 2010). With the popularity of MOM hips reaching $35 \%$ of total hip replacements performed, there has been a plethora of articles focused on metal abrasion, corrosion, and resultant tissue response around implants (Grupp et al. 2009; Kwon et al. 2009; Sicilia et

\footnotetext{
* Correspondence: dlionbergermd@gmail.com

${ }^{1}$ Southwest Orthopedic Group LLC, 6560 Fannin Street, Suite 1016, Scurlock

Tower, Houston, TX 77030, USA

Full list of author information is available at the end of the article
}

al. 2008; Willert et al. 2005). While corrosion may not create as much local tissue hypertrophy, the seemingly asymptomatic MOM hip can cause reactions around the implant, which manifests as pseudo tumor or an aseptic lymphocyte-dominated vasculitis-associated lesion (ALVAL). This ALVAL reaction has become more commonly known as the MOM hypersensitization, which may have created tissue hyperplasia in MOM total hips (Bisschop et al. 2013; Demehri et al. 2014; Gao et al. 2011; Hart et al. 2012; Jacobs and Hallab 2006; Latteier et al. 2011; Schafer et al. 2001; Thomas et al. 2006). A mechanism behind the formation of this tissue injury appears to be metal byproducts of wear such as ionized forms of chromium and nickel which stimulate T-cell sensitization (Caicedo et al. 2013; Ikarashi et al. 2002; Lohmann et al. 2013).

Serum metal ion levels may be elevated in normally functioning implants and ion levels do not accurately predict outcomes of patient satisfaction or implant 
function (Lachiewicz et al. 2016; Luetzner et al. 2007). While metal ion levels are not a reliable predictor of potential implant failure, a patient's metal sensitivity status may be a factor in implant failure. The incidence of nickel $(\mathrm{Ni})$ and chromium $(\mathrm{Cr})$ sensitivity in the normal population is approximately 10\% (Hallab et al. 2001; Reich et al. 2010). If one has an implant in place, metal exposure may cause the incidence of sensitization to rise as high as 25\% (Bloemke and Clarke 2015; Hallab et al. 2001). If the implant mechanically fails, because of loosening or other causes, the incidence can be as high as $60 \%$ (Hallab et al. 2001). Testimony to the existence of implant allergy exists not only in skin testing, but also in the histologic testing of T-cell reactivity. Rather than dermatological testing, a more direct and objective T-cell reactivity assay, better known as lymphocyte transformation test (LTT) is used to evaluate for an allergic response. This assay tests for proliferation of peripheral blood lymphocytes in response to a specific immunological challenge such as nickel, cobalt, chromium, iron, or other trace elements (Niki et al. 2005). Proliferation of lymphocytes in response to one of these potential allergens is indicative of a delayed-type (type IV) allergic response. While dermatologic testing may be simpler to perform, the advantage of the LTT is the reduction of false positives and enhanced specificity-especially when testing for metal byproducts of wear-as compared to skin testing (Carando et al. 1985). It avoids confounding variation of metal concentrations used in the dermatologic contact tests and eliminates the subjectivity of skin test interpretation by shifting to an objective numerical value on an assay (Mihalko et al. 2012).

The histological response to a metal allergen is best described as a T-cell-mediated type of hypersensitivity, characterized by activation of both $\mathrm{CD}^{+}$and $\mathrm{CD} 8^{+}$ T-cells (Cavani et al. 2003). Delayed-type hypersensitivity reactions to poison ivy and autoimmune disease are well described in the literature (Usatine and Riojas 2010). However, type IV hypersensitivity in orthopedic implants is less understood (Hallab et al. 2001). This activation process initiates when metal ions behave as haptens, activating $\mathrm{CD}^{+}$cells. Activated $\mathrm{CD} 4^{+}$cells produce cytokines such IFN-gamma, TNF-alpha, IL-17, IL-22, and ultimately IL-12 (Hallab et al. 2001; Kumar et al. 2010; Lachiewicz et al. 2016). The resulting activation of the $\mathrm{Th}_{17}$ cell line by these cytokines can then induce an inflammatory response that may persist for a long period of time, thus creating the memory effect of what is classically seen in simple skin reactions. This activation cascade may serve as the mechanism of cellular reactivity to metal byproducts that was previously thought unlikely.

This study specifically focuses on metal allergy in patients who have undergone total knee arthroplasty (TKA). When assessing the painful TKA, there are often patients without mechanical or functional findings and often-vague pain for which no apparent explanations for their pain exist (Caicedo et al. 2014). A delayed-type hypersensitivity reaction to metal orthopedic implants is a plausible factor that may contribute to some of these failures (Bergschmidt et al. 2012; Schroer et al. 2013). If hypersensitivity reactions to specific metals like nickel do indeed contribute to TKA failure, one should see a histological response of delayed-type hypersensitivity reactions in failed knees. In this study, we sought to assess the presence of immunologic $\mathrm{CD} 4^{+}$and $\mathrm{CD} 8^{+}$staining in sections taken from a sequential series of revision TKA patients who were revised for implant failure unrelated to infection or mechanical malfunction and all of whom had undergone lymphocyte transformation testing (LTT) for sensitivity to nickel. We then evaluated the histologic response differences between those sensitive to nickel and a non sensitive control group. The histological findings were also compared to functional and clinical Knee Society scores assessed before and after surgical revision.

\section{Methods \\ Allergy testing}

This study was approved by the Houston Methodist Institutional Review Board (No. 12712) and was conducted in accordance with the Declaration of Helsinki. All participants in the study provided written informed consent, testing was self funded by patients. Lymphocyte transformation test (Orthopedic Analysis LLC, Chicago IL) was used to determine if patients were hypersensitive to nickel. The proliferation index is the main result of this assay, it is the ratio of proliferation of lymphocytes exposed to a metal antigen to those exposed to a negative control, measured by radiation counts per minute. A proliferation index of less than 4 is considered no to low reactivity, while greater than 4 is considered reactive to highly reactive, defined as a statistically significant $>4$ fold proliferation index response, $p<0.05$ ). The patients who had a LTT $<4$ were classified as controls and patients who had a LTT $>4$ were classified as nickel sensitive. One week prior to testing, the patients were taken off immunologic-suppressive agents including NSAIDs, which could compromise the sensitivity of the test.

\section{Patient selection}

The sequential series of 46 total patients experiencing painful symptomatic total knee arthroplasty deemed revisable without a past medical history of an allergic reaction to a metal implant. Index implants included nickel containing devices from a variety of name brand companies including Zimmer Biomet, Smith \& Nephew, and Stryker. Each patient was evaluated with anterior/posterior, lateral, and individual component spot view radiographs to assess for implant malposition, patients with 
concern for instability underwent stress radiographs to rule out ligament instability. Experimental subjects included patients whose findings were merely discomfort, swelling, instability including fibrosis restricting range of motion, or functional dissatisfaction without significant radiographic findings and were classified as "non-radiographic" meaning that these patients were unsatisfied with their implants without a specific radiographic cause. We chose for comparison this group of patients because we hypothesized that the unexplained, non-radiographic failure could be explained by an allergic response to the implant in the nickel sensitive group. 28 patients were assigned to the nickel sensitive group according to the results of an LTT demonstrating reactive nickel sensitivity. 18 patients had no to low reactivity of the LLT and were classified as controls. Those patients who demonstrated excessive wear byproducts by radiographically-significant polyethylene wear or arthroplasty usages of greater than 2 years were excluded from comparison, as high concentrations of wear byproducts may increase the background cellular reactivity of the $\mathrm{CD}^{+}$cell line to overshadow the increase in the $\mathrm{CD}^{+}$cell line, masking metal reactivity. 7 such patients were excluded in the nickel sensitive group and 4 were excluded in the control group. Infection exclusion criteria included elevated serum erythrocyte sedimentation rate and C-reactive protein, synovial leukocyte count, synovial neutrophil percentage, presence of purulence, culture, and $>5$ neutrophils per high power field $\times 5$ fields at $400 \times$ (Parvizi et al. 2011), in addition patients with a synovial biopsy containing $\geq 5$ neutrophils per high power field $\times 5$ fields at $400 \times$ were excluded from the study. This excluded 2 patients in the nickel sensitive group and 1 in the control group. After these exclusions, our cohort included 32 patients total: 19 in the nickel sensitive group ( 7 male, 12 female, average age 65, range 44-81) and 13 in the control group (6 male, 7 female, average age 63 , range $46-82$ ).

\section{Pathology}

Surgical specimens were biopsied from the synovial membrane of knee directly inferior to the patella at the time of surgery for intraoperative evaluation to rule out infection and for routine clinical processing. This location was chosen due to consistent access and the degree of inflammation in this area. The formalin fixed and paraffin embedded sections were evaluated on hematoxylin and eosin stains to identify the areas with highest concentration of lymphocytic infiltration. The same sections were than stained with $\mathrm{CD}_{4}^{+}$and $\mathrm{CD}^{+}$immunohistochemical stains (Ventana, Tucson, Arizona, USA), to assess the infiltration of $\mathrm{CD}^{+}$and $\mathrm{CD} 8+$ cells in the synovium. The histological sections were read by 2 independent investigators and scored for the number of $\mathrm{CD}^{+}$and $\mathrm{CD}^{+}{ }^{+}$-lymphocytes per high-power field. A ratio of $\mathrm{CD}^{+} / \mathrm{CD} 8^{+} \mathrm{T}$-cells was then calculated. $\mathrm{CD} 4^{+}$ T-cells, indicative of delayed-type hypersensitivity, were a presumed indication of metal sensitization.

\section{Surgery}

All surgeries were performed in the same fashion by the same surgeon in the same institution. Both arms were revised using a constrained posterior cruciate-sacrificing implant with a multi-layer zirconium nitride-coated CoCr29Mo6 base material implant designed for reduced ion and wear byproduct emission in either an allergic sensitive Columbus $(n=29)$ or EnduRo ${ }^{m}(n=3)$ AS knee revision system (Aesculap, Tuttlingen, Germany).

\section{Patient follow-up}

Follow-up in both cohorts after surgical revision of implant failure was 2.5 years. Assessments for length of stay and adverse events were also evaluated as were any long-term complications out to 2 years. Functional and clinical (Knee Society Clinical Rating System) scores along with range of motion evaluations were performed at each postoperative visit to compare them to baseline values obtained prior to surgery. The functional score is measured from 0 to 100 and includes the number of blocks one can walk, the ability to use stairs, and the type of walking aid used. The clinical score is also measured from 0 to 100 and measures pain, amount of flexion contracture, extension lag, total range of flexion, alignment, and antero-posterior/mediolateral stability. The differences in the pre-operative and post-operative scores were calculated. To supplement the insensitivity of the Knee Society Score, patients were also assessed by personal interview for subjective improvement after revision to see if they were happy with their result and felt it was worthwhile to do the revision.

\section{Statistics}

Statistics were performed using SPSS. A Shapiro-Wilk normality test was used to determine the normality of the $\mathrm{CD}^{+}{ }^{+} \mathrm{CD}^{+}{ }^{+}$ratio data set. It was determined that this data was not normally distributed $(p<.001)$. Differences between the ratio of $\mathrm{CD}^{+}{ }^{+} \mathrm{CD}^{+}$cells were compared between groups using a nonparametric 2-tailed Mann-Whitney U test at a 95\% significance level. Cell counts, functional score, clinical score, and range of motion were compared between groups using a 2-tailed $t$ test at a $95 \%$ significance level. To determine the appropriate sample size of the study, several assumptions were made for the $t$ test employed to determine significance of the endpoint outcome. First, a two-tailed distribution was used with level $\alpha=0.05$ representing $5 \%$ probability of type I error, or equivalently, $5 \%$ probability of a false positive. Next, the power was established at the $90 \%$ representing $10 \%$ probability of type II error, or equivalently, 
$10 \%$ probability of a false negative. A-priori statistics were determined to compute the sample size. The meaningful effect size for our proposed study was chosen to be 0.5 . Taking these a-priori statistics into consideration, the size of the study was computed to be a total of 35 subjects.

\section{Results}

In the nickel sensitized group of patients, there was a significant increase in $\mathrm{CD} 4^{+}$reactivity compared to the $\mathrm{CD}^{+}$reactivity, while the control group showed lower amounts of inflammatory $\mathrm{CD} 4^{+}$cells (Fig. 1). There was significant increase in the ratio of $\mathrm{CD}^{+} / \mathrm{CD}^{+}$lymphocyte activity between the nickel sensitive and control groups (Fig. 2). The average ratio was 1.28 in the nickel sensitive group, almost a $70 \%$ increase than that of the control average of 0.76 ( $p$ value $=0.009$ ). There is a higher trending number of $\mathrm{CD} 4^{+}$lymphocytes in nickel sensitive patients, as shown in (Fig. 3). With greater than 2.5 year follow-up, the nickel sensitive patients, for which there was no radiographic explanation or functional aberrance to explain their chronic pain, demonstrated an average improvement of the functional knee score by over 28 points, the clinical score by 25 points, and the range of motion by 16 degrees, as shown in (Fig. 4). These functional, clinical and range of motion improvements were like those seen in the control group; there was no difference seen between the nickel sensitive and control groups. In addition to the functional knee score, clinical knee score, and range of motion results, patients were assessed for subjective improvement after revision. 14 out of 19 nickel sensitive patients (74\%) noted improvement after revision. In this group, 3 patients developed stem pain for which revision to a larger stem corrected their symptoms. 1 more revision was performed for instability. Another 2 patients reported dissatisfaction with their outcomes initially without clinical signs of implant complication, although after 1 year of follow-up, 1 of these patient's dissatisfaction was resolved. No infections occurred in either group. No chronic effusion or dermatologic manifestation of continued allergic response was seen in either group. There were no revisions in the control group.

\section{Discussion}

The goal of this study is to examine the synovial cell counts of patients who are sensitive to nickel, as identified by the LTT. The study showed a statistically significant $(p=0.009)$ increase in the $\mathrm{CD} 4^{+} / \mathrm{CD}^{+}$ratio in nickel sensitive patients by almost $70 \%$. In addition, patients improved in function using a metal byproduct reducing implant to an equivalent level as those in the control group without a metal sensitivity. Patients with

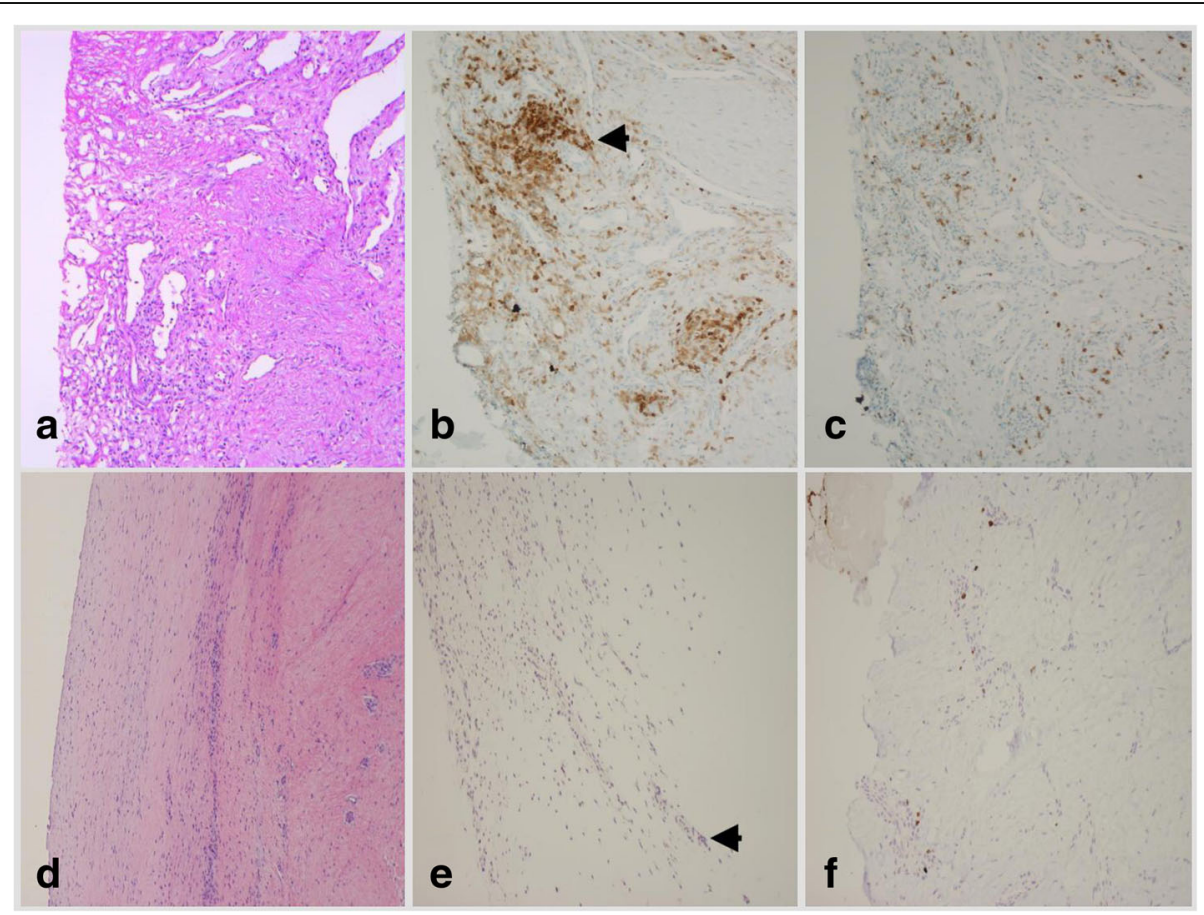

Fig. 1 (a) Chronic inflammatory nidus in a nickel-sensitive synovium after total knee arthroplasty (H\&E $\times 40)$. Immunohistochemical staining for $\mathrm{CD}^{+}{ }^{+}$-cell $(\mathbf{b})$ and $\mathrm{CD}^{+} \mathrm{T}$ cell $(\mathbf{c})$ markers shows a relative predominance of $\mathrm{CD} 4^{+}$infiltrate, consistent with a delayed-type hypersensitivity $\left(\mathrm{CD}^{+}\right.$immunohistochemistry $\left.X 40\right)$. (d) Synovial sample from a patient in the control group (H\&E $\times 40$ ). Immunohistochemical staining for $\mathrm{CD}^{+} \mathrm{T}$ cell $(\mathbf{e})$ and $\mathrm{CD} 8^{+} \mathrm{T}$ cell $(\mathbf{f})$ markers shows similar levels of inflammatory infiltrate $\left(\mathrm{CD} 8^{+}\right.$immunohistochemistry $\left.\times 40\right)$. Black arrowhead denotes CD4+ staining cells 


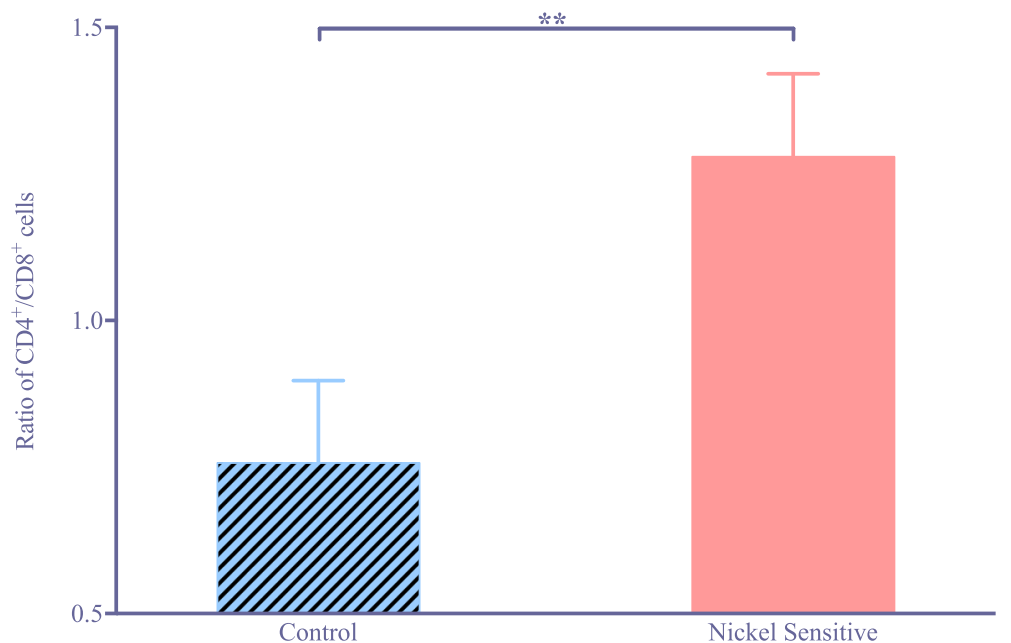

Fig. 2 Comparison of the ratio of $\mathrm{CD}^{+}$to $\mathrm{CD}^{+}$T cells between control $(n=13)$ and nickel sensitive $(n=19)$ groups. The control average is 0.76 and the nickel sensitive average is 1.28. Error bars show standard error. ${ }^{* *}$ Indicates $p=0.009$

positive LTT findings prior to revision surgery of the knee may have a higher dissatisfaction with their postoperative result. While confirmation of allergic sensitization by $\mathrm{CD} 4^{+} / \mathrm{CD}^{+}$ratio may provide a clue in suspected synovial samples, it is not sensitive enough to rely on without indolent LTT testing. Rather, this novel testing provides experimental evidence of the existence of metal hypersensitivity in failed TKA. Our histological results are consistent with a type IV delayed-type hypersensitivity reaction occurring in metal sensitive patients. The increased ratio of $\mathrm{CD}^{+} / \mathrm{CD}^{+}$ cells on histology was a significant finding in the nickel sensitive group. While some enhancement of $\mathrm{CD}^{+}$activity is noted in both groups, this would typically be expected as all implants exhibit some wear debris load due to years of use. This, in fact, was demonstrated by our results in this study. Notably, the most profound ratio values are found in recently implanted patients where the $\mathrm{CD}^{+}$cell line has not yet matured as a response to wear byproduct burden. Further, this series was derived from patients with a positive metal sensitivity and painful, failed total knee arthroplasty where no mechanical etiology of failure was apparent except fibrosis and loss of range of motion.

Work by numerous authors has suggested that a delayed type T-cell hypersensitivity is possible in a logical cascade of patients with failed joint replacement (Bisschop et al. 2013; Lohmann et al. 2013). In women the incidence of metal sensitization is higher because of their use of dental, jewelry and cosmetic products all of which cause increased exposure to metal (Ikarashi et al. 2002; Sicilia et al. 2008). In patients who have orthopedic implants, as compared to the normal population, the incidence of metal sensitization reaches $25 \%$

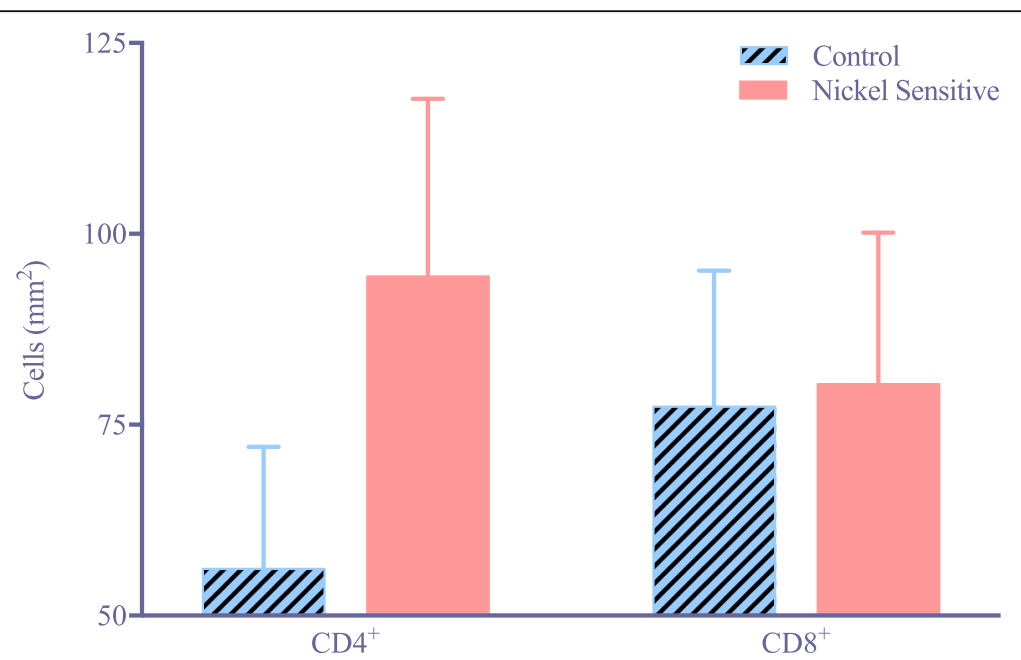

Fig. 3 Comparison of $\mathrm{CD}^{+}$and $\mathrm{CD} 8^{+}$T cell counts between control $(n=13)$ and nickel sensitive $(n=19)$ groups. Control patient synovial samples show a trend of less $C D 4^{+}$counts relative to nickel sensitive samples. Error bars show standard error 


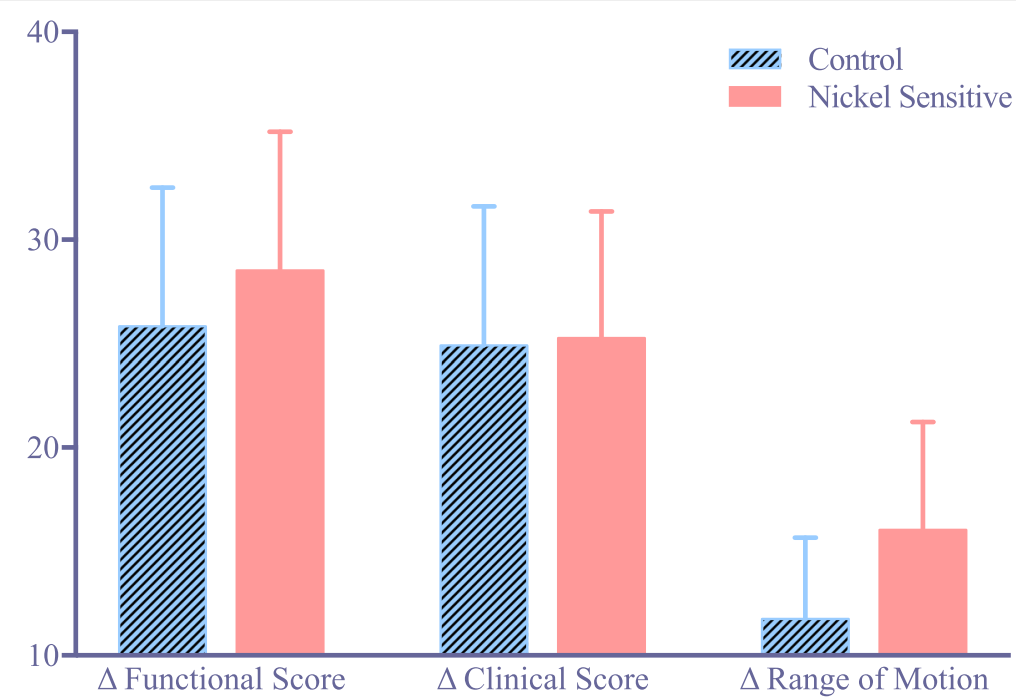

Fig. 4 Average increase in range of motion, clinical, and functional Knee Society scores between control and nickel sensitive patients. Error bars show standard error. No significant difference in improvement of functional score, clinical score, or range of motion was found between the control $(n=13)$ and nickel sensitive $(n=19)$ groups

(Mihalko et al. 2012). If the implant happened to be functioning poorly, the incidence is even higher. These patients have implants which are not radiographically loose, lax, or compromised mechanically except in limited range of motion. Why did these patients fail to properly rehab from their replacement in the absence of imbalance of gap balancing, loosening, or mechanical limitation? The validation of this with histology suggests the hypothesis that allergic sensitization and allergic reaction in TKA may in fact play a role in unexplained joint pain.

In our series of patients, the incidence of nickel sensitization in poorly functioning implants was similar to those of previous studies who could not attribute symptoms to a known cause. Our percentage of 59\% nickel sensitivity (19 out of 32 knees without radiographic cause for failure) compares to that of other authors (10\% general, $25 \%$ implanted, and $60 \%$ poor performing implants) (Hallab et al. 2001; Jacobs and Hallab 2006; Mihalko et al. 2012; Schroer et al. 2013). This series demonstrated a satisfactory functional improvement in the metal sensitive group where no obvious clinical condition which could explain their pain was present. While not ordinarily considered an impressive outcome, this series compares favorably with many authors' findings of patients with unexplained knee pain (Caicedo et al. 2013; Cherian et al. 2016; Elmallah et al. 2016; Hitt et al. 2015; McNabb et al. 2015; Meneghini et al. 2015; Petersen et al. 2015; Schroer et al. 2013; Siqueira et al. 2015; Watters et al. 2010; Wilke et al. 2015), particularly knee pain that cannot be explained radiographically (Mont et al. 1996). This series demonstrates that the influence of metal sensitization was apparent and was subsequently corrected by removal of the antigenic byproducts of wear.
The revision of 4 of the total nickel sensitive group $(n=19)$ represents $21 \%$ failure at 2.5 years. This rate is similar to other authors where cementless hybrid stems were used and $17 \%$ failed at 2 years compared to $32 \%$ of the cemented stems (Edwards et al. 2014). Likewise, in a different series of 84 patients fifty-year-old or younger, 27\% failed for any reason at 10 years (Aggarwal et al. 2014). An incidence of $35 \%$ visible stem hypertrophy was noted in the first year. At 3-year-follow-up, no further revisions were done and half without a cessation of tip-of-stem pain. What is worrisome is the frequency of early stem hypertrophy in the long stem cementless hybrid group of patients in which $20 \%$ were still considered at risk for continued or impending failures from continued increasing modular mismatch and cortical hypertrophy. The design of implant may influence the outcome such as hybrid cementless long stems in women prone to osteopenia and modulous mismatch. While women were more prone to this, it was apparent in both male and female patients where these stems are used (solid cobalt chrome coated stems). Surgeons should counsel patients when this choice of stem is used. Furthermore surgeons need to give realistic expectations to those patients undergoing TKA revision who are sensitive to nickel, in this report only $75 \%$ of patients were satisfied with their revision and 1 in 4 required further revision surgery.

There are weaknesses and limitations to this study. As with any initial assessment into a preliminary report, we strove to get the best histological sampling possible. Inevitably, the histological sectioning of the most inflamed region of tissues (always in the patellar recess) may either over or under represent the general reaction. Inflammation is also present in byproducts of wear as well 
as with loosening of implants. However, it is the $\mathrm{CD} 4^{+}$ antigenic immunologic staining which is more prominent in delayed-type hypersensitivity reactions, whereas in loose or unstable TKA, high loads of byproducts of wear are present resulting in $\mathrm{CD}^{+}$cellular hyperplasia. It is with this difference in reactivity and stain uptake that we sought to eliminate the lack of differentiation that exists on histological sections of $\mathrm{H} \& \mathrm{E}$ staining, which generally reveals inflammation, but does not distinguish from which cell line the inflammation originated. Although nickel sensitization, as measured by LTT, was associated with a higher $\mathrm{CD} 4^{+} / \mathrm{CD}^{+}$ratio, this does not determine absolute causality. An elevated $\mathrm{CD} 4^{+} / \mathrm{CD} 8^{+}$ratio would be expected to be seen in any Type-IV inflammatory reaction. This could be attributed to sensitivity to other metals present in implants, polyethylene insert, exposure to metals from surgical instruments and saws, or bone cement exposure.

The implant used in these revisions was exclusively that of an allergy-sensitive resistive implant. It allegedly reduces, but does not eliminate, the wear byproducts. Just as other implants attempt to reduce the immunogenic load through implants such as molybdenum, coatings, all-poly trays, and cement bed incorporation to contain exposures to raw metal surfaces, total elimination of metal byproducts has not been achieved. To give the best possible reduction in immunogenic exposure, a ceramic-coated implant was used to provide this relative reduction to best validate our study results postoperatively. While a cohort of coated versus non-coated implants might provide more evidence for allergy existence in the future, this study may provide more immediate information for the surgeon to be able to counsel patients when less obvious reasons for knee pain exists, short of an allergic sensitization. This is the first reported series of patients with known metal sensitization according to an LTT, which shows a histologically different synovium from a control, giving some credence to the fact that metal sensitivity may be a more important etiology of radiographically-unexplained implant failure than initially appreciated. In addition, use of an LTT test in high risk or self-proclaimed metal sensitive patients may be of value to consider in the future so as to document and have on hand appropriate metal wear reduced implants for use in such high-risk patients. This information can also be useful for educating insurance companies on the necessity of coated implants in patients with known metal allergies. The evaluation of a $\mathrm{CD} 4^{+}$/ $\mathrm{CD}^{+}$ratio in samples of synovium is neither sensitive nor specific enough on its own to define metal allergies in patients. LTT can be positive in a patient with a metal allergy unrelated to an implant, while an elevated CD4/ CD8 ratio however is more specific for an inflammatory reaction occurring in the joint synovium. The results of this study indicate that metal sensitivity may exist and may be an important factor to consider in implant selection. Moreover, a patient's synovial $\mathrm{CD} 4^{+} / \mathrm{CD} 8^{+}$ratio may be a useful addition to the LTT and clinical suspicion in determining the etiology of early failed knees.

As more vendors are offering metal byproduct reduced coatings and/or alloys, which are consistent, allergic sensitization may be less of an issue in the future. While not a huge source of implant complications, metal byproduct allergy may play a larger role than previously suspected.

\section{Abbreviations \\ ALVAL: aseptic lymphocyte-dominated vasculitis-associated lesion; LLT: lymphocyte stimulation test; MOM: metal-on-metal; TKA: total knee arthroplasty}

\section{Availability of data and materials}

Data will be made available upon request.

\section{Authors' contributions}

$D L$ conceived of the study, performed the surgeries, and assisted with manuscript preparation. JS participated in data collection, data interpretation, statistical analysis, and assisted with manuscript preparation. CW participated in data collection, data interpretation, and assisted with manuscript preparation. AR performed the immunohistochemistry. All authors read and approved the final manuscript.

\section{Ethics approval and consent to participate}

This study was approved by the Houston Methodist Institutional Review Board (No. 12712) and was conducted in accordance with the Declaration of Helsinki. All participants in the study provided written informed consent.

\section{Competing interests}

No authors have any competing interests except $\mathrm{DL}$, the principal investigator of this study, who has received research monies from Pfizer (New York, New York) and Aesculap (Tuttlingen, Germany). DL has also received consulting fees from Aesculap (Tuttlingen, Germany). This particular study was self-funded.

\section{Publisher's Note}

Springer Nature remains neutral with regard to jurisdictional claims in published maps and institutional affiliations.

\section{Author details}

${ }^{1}$ Southwest Orthopedic Group LLC, 6560 Fannin Street, Suite 1016, Scurlock Tower, Houston, TX 77030, USA. ${ }^{2}$ Texas A\&M College of Medicine, Houston Methodist Hospital, 6565 Fannin Street, Houston, TX 77030, USA. ${ }^{3}$ Scott \& White Memorial Hospital, 2401 S. 31st St, Temple, TX 76508, USA

${ }^{4}$ Department of Pathology, Houston Methodist Hospital, 6565 Fannin Street, Suite M227, Houston, TX 77030, USA

Received: 13 March 2018 Accepted: 26 July 2018

Published online: 14 August 2018

\section{References}

Aggarwal VK, Goyal N, Deirmengian G, Rangavajulla A, Parvizi J, Austin MS (2014) Revision total knee arthroplasty in the young patient: is there trouble on the horizon? J Bone Joint Surg Am 96:536-542. https://doi.org/10.2106/JBJS.M.00131

Beecker J, Gordon J, Pratt M (2009) An interesting case of joint prosthesis allergy. Dermatitis 20:E4-E9. https://doi.org/10.2310/6620.2009.08087

Bergschmidt P, Bader R, Mittelmeier W (2012) Metal hypersensitivity in total knee arthroplasty: revision surgery using a ceramic femoral component - a case report. Knee 19:144-147. https://doi.org/10.1016/j.knee.2011.01.001

Bisschop R, Boomsma MF, Van Raay JJ, Tiebosch AT, Maas M, Gerritsma CL (2013) High prevalence of pseudotumors in patients with a Birmingham hip resurfacing prosthesis: a prospective cohort study of one hundred and 
twenty-nine patients. J Bone Joint Surg Am 95:1554-1560. https://doi.org/10. 2106/JBJS.L.00716

Bloemke AD, Clarke HD (2015) Prevalence of self-reported metal allergy in patients undergoing primary total knee arthroplasty. J Knee Surg 28:243-246. https://doi.org/10.1055/s-0034-1381959

Caicedo MS, Samelko L, Hallab NJ (2013) Lymphocyte reactivity to nickel correlates with reported high-pain levels in patients with Total joint arthroplasties: implications for pain-related hypersensitivity responses metalon-metal Total hip replacement devices:99-112 doi:https://doi.org/10.1520/ STP156020120025

Caicedo MS, Solver E, Coleman L, Hallab NJ (2014) Metal Sensitivities Among TJA Patients with Post-Operative Pain: Indications for Multi-Metal LTT Testing. J Long Term Eff Med Implants 24:37-44. https://doi.org/10.1615/ JongTermEffMedlmplants.2014010261

Carando S, Cannas M, Rossi P, Portigliatti-Barbos M (1985) The lymphocytic transformation test (L.T.T.) in the evaluation of intolerance in prosthetic implants. Ital J Orthop Traumatol 11:475-481

Cavani A, Nasorri F, Ottaviani C, Sebastiani S, De Pita O, Girolomoni G (2003) Human CD25+ regulatory $T$ cells maintain immune tolerance to nickel in healthy, nonallergic individuals. J Immunol 171:5760-5768. https://doi.org/10. 4049/jimmunol.171.11.5760

Cherian JJ, Bhave A, Harwin SF, Mont MA (2016) Outcomes and Aseptic Survivorship of Revision Total Knee Arthroplasty. Am J Orthop (Belle Mead NJ) 45:79-85

Demehri S, Cunningham TJ, Hurst EA, Schaffer A, Sheinbein DM, Yokoyama WM (2014) Chronic allergic contact dermatitis promotes skin cancer. J Clin Invest 124:5037-5041. https://doi.org/10.1172/JCI77843

Edwards PK, Fehring TK, Hamilton WG, Perricelli B, Beaver WB, Odum SM (2014) Are cementless stems more durable than cemented stems in two-stage revisions of infected total knee arthroplasties? Clin Orthop Relat Res 472:206211. https://doi.org/10.1007/s11999-013-3139-8

Elmallah RK, Cherian JJ, Harwin SF, Mont MA (2016) Implant Designs in Revision Total Knee Arthroplasty. Am J Orthop (Belle Mead NJ) 45:75-78

Gao X, He RX, Yan SG, Wu LD (2011) Dermatitis associated with chromium following total knee arthroplasty. J arthroplasty 26(665):e613-e666. https:// doi.org/10.1016/j.arth.2010.06.002

Grupp TM, Stulberg D, Kaddick C, Maas A, Fritz B, Schwiesau J, Bloemer W (2009) Fixed bearing knee congruency -- influence on contact mechanics, abrasive wear and kinematics. Int J Artif organs 32, 213:-223. https://doi.org/10.1177/ 039139880903200405

Hallab N, Merritt K, Jacobs JJ (2001) Metal sensitivity in patients with orthopaedic implants. J Bone Joint Surg Am 83-A:428-436. https://doi.org/10.2106/ 00004623-200103000-00017

Handa S, Dogra S, Prasad R (2003) Metal sensitivity in a patient with a total knee replacement. Contact Dermatitis 49:259-260. https://doi.org/10.1111/j.01051873.2003.0225b.x

Hart AJ et al (2012) Pseudotumors in association with well-functioning metal-onmetal hip prostheses: a case-control study using three-dimensional computed tomography and magnetic resonance imaging. J Bone Joint Surg Am 94:317-325. https://doi.org/10.2106/JBJS.J.01508

Hitt K, Bhowmik-Stoker M, Howard M, Mittal Y, Heekin RD, Jacofsky D (2015) Joint line restoration in a contemporary revision knee system. J Knee Surg 28:7582. https://doi.org/10.1055/s-0034-1368144

Ikarashi Y, Tsuchiya T, Toyoda K, Kobayashi E, Doi H, Yoneyama T, Hamanaka H (2002) Tissue Reactions and Sensitivity to Iron-Chromium Alloys Materials Transactions 43:3065-3071 doi: https://doi.org/10.2320/matertrans.43.3065

Jacobs JJ, Hallab NJ (2006) Loosening and osteolysis associated with metal-onmetal bearings: a local effect of metal hypersensitivity? J Bone Joint Surg Am 88:1171-1172. https://doi.org/10.2106/JBJS.F.00453

Kumar V, A. A, J. A (2010) Robbins and Cotran pathologic basis of disease, 8th edn. Saunders Elsevier, Philadelphia, PA

Kwon YM, Xia Z, Glyn-Jones S, Beard D, Gill HS, Murray DW (2009) Dosedependent cytotoxicity of clinically relevant cobalt nanoparticles and ions on macrophages in vitro. Biomed Mater 4:025018. https://doi.org/10.1088/1748$6041 / 4 / 2 / 025018$

Lachiewicz PF, Watters TS, Jacobs JJ (2016) Metal Hypersensitivity and Total Knee Arthroplasty. J Am Acad Orthop Surg 24:106-112. https://doi.org/10.5435/ JAAOS-D-14-00290

Latteier MJ, Berend KR, Lombardi AV Jr, Ajluni AF, Seng BE, Adams JB (2011) Gender is a significant factor for failure of metal-on-metal total hip arthroplasty. J Arthroplasty 26:19-23. https://doi.org/10.1016/j.arth.2011.04.012
Lohmann CH et al (2013) Periprosthetic tissue metal content but not serum metal content predicts the type of tissue response in failed small-diameter metal-on-metal total hip arthroplasties. J Bone Joint Surg Am 95:1561-1568. https://doi.org/10.2106/JBJS.L.01273

Luetzner J, Krummenauer F, Lengel AM, Ziegler J, Witzleb WC (2007) Serum metal ion exposure after total knee arthroplasty. Clin Orthop Relat Res 461: 136-142. https://doi.org/10.1097/BLO.0b013e31806450ef

McNabb DC, Kim RH, Springer BD (2015) Instability after total knee arthroplasty. J Knee Surg 28:97-104. https://doi.org/10.1055/s-0034-1396080

Meneghini RM, Mont MA, Backstein DB, Bourne RB, Dennis DA, Scuderi GR (2015) Development of a Modern Knee Society Radiographic Evaluation System and Methodology for Total Knee Arthroplasty. J Arthroplasty 30:2311-2314. https://doi.org/10.1016/j.arth.2015.05.049

Mihalko WM, Goodman SB, Hallab NJ, Jacobs JJ (2012) Skin patch testing and associated total knee outcomes AAOS Now 9

Mont MA, Serna FK, Krackow KA, Hungerford DS (1996) Exploration of radiographically normal total knee replacements for unexplained pain. Clin Orthop Relat Res 331:216-220. https://doi.org/10.1097/00003086-19961000000030

Niki Y, Matsumoto H, Otani T, Yatabe T, Kondo M, Yoshimine F, Toyama Y (2005) Screening for symptomatic metal sensitivity: a prospective study of 92 patients undergoing total knee arthroplasty Biomaterials 26:1019-1026 doi: https://doi.org/10.1016/j.biomaterials.2004.03.038

Parvizi J et al (2011) New definition for periprosthetic joint infection: from the workgroup of the musculoskeletal infection society. Clin Orthop Relat Res 469:2992-2994. https://doi.org/10.1007/s11999-011-2102-9

Petersen KK, Simonsen O, Laursen MB, Nielsen TA, Rasmussen S, Arendt-Nielsen L (2015) Chronic postoperative pain after primary and revision total knee arthroplasty. Clin J Pain 31:1-6. https://doi.org/10.1097/AJP. 0000000000000146

Reich J, Hovy L, Lindenmaier HL, Zeller R, Schwiesau J, Thomas P, Grupp TM (2010) Preclinical evaluation of coated knee implants for allergic patients. Orthopade 39:495-502. https://doi.org/10.1007/s00132-009-1581-9

Repantis T, Vitsas V, Korovessis P (2013) Poor mid-term survival of the low-carbide metal-on-metal Zweymuller-plus total hip arthroplasty system: a concise follow-up, at a minimum of ten years, of a previous report*. J Bone Joint Surg Am 95:e331-e334. https://doi.org/10.2106/JBJS.L.00031

Schafer T et al (2001) Epidemiology of contact allergy in adults. Allergy 56:11921196. https://doi.org/10.1034/j.1398-9995.2001.00086.x

Schroer WC et al (2013) Why are total knees failing today? Etiology of total knee revision in 2010 and 2011. J Arthroplasty 28:116-119. https://doi.org/10.1016/ j.arth.2013.04.056

Sicilia A, Cuesta S, Coma G, Arregui I, Guisasola C, Ruiz E, Maestro A (2008) Titanium allergy in dental implant patients: a clinical study on 1500 consecutive patients. Clin Oral Implants Res 19:823-835. https://doi.org/10. 1111/j.1600-0501.2008.01544.x

Siqueira MB, Klika AK, Higuera CA, Barsoum WK (2015) Modes of failure of total knee arthroplasty: registries and realities. J Knee Surg 28:127-138. https://doi. org/10.1055/s-0034-1396014

Thomas P, Bandl WD, Maier S, Summer B, Przybilla B (2006) Hypersensitivity to titanium osteosynthesis with impaired fracture healing, eczema, and T-cell hyperresponsiveness in vitro: case report and review of the literature. Contact Dermatitis 55:199-202. https://doi.org/10.1111/j.1600-0536.2006. 00931.x

Usatine RP, Riojas M (2010) Diagnosis and management of contact dermatitis. Am Fam Physician 82:249-255

Watters TS, Cardona DM, Menon KS, Vinson EN, Bolognesi MP, Dodd LG (2010) Aseptic lymphocyte-dominated vasculitis-associated lesion: a clinicopathologic review of an underrecognized cause of prosthetic failure Am J Clin Pathol 134:886-893. https://doi.org/10.1309/AJCPLTNEUAH8XI4W

Wilke B, Wagner E, Trousdale R (2015) Long-term survival of a semi-constrained implant following revision for infection. J Arthroplasty 30:808-812. https:// doi.org/10.1016/j.arth.2014.10.037

Willert HG, Buchhorn GH, Fayyazi A, Flury R, Windler M, Koster G, Lohmann CH (2005) Metal-on-metal bearings and hypersensitivity in patients with artificial hip joints. A clinical and histomorphological study. J Bone Joint Surg Am 87: 28-36. https://doi.org/10.2106/JBJS.A.02039pp 